\title{
Magnetic anomalies in the Shikoku Basin: a new interpretation
}

\author{
Nicolas Chamot-Rooke ${ }^{1}$, Vincent Renard ${ }^{2}$ and Xavier Le Pichon ${ }^{1}$ \\ 'Département de Géologie (CNRS UA 215), Ecole Normale Supérieure. 24 Rue Lhomond, Paris (France) \\ 'IFREMER, Centre Océanologique de Bretagne, B.P. 337, Brest (France)
}

Revised version accepted October 17, 1986

\begin{abstract}
Kaiko surveys over the Nankai Trough made available new magnetic and structural data for the northern Shikoku Basin. A survey of the oceanic lithosphere subducting below Southwest Japan along the central Nankai Trough revealed the existence of several north-south basement troughs. They are probably transform faults related to a north-south spreading system. We examine the possibility of a late phase of north-south spreading limited to the axial northernmost Shikoku Basin, active between 14 and $12 \mathrm{Ma}$. If this system was already active before that time, i.e. during the $\mathrm{N} 55^{\circ}$ opening of the southeastern basin, then a triple junction should be found between both areas.

Based on these data and previous studies we present a new interpretation of magnetic anomalies over the whole basin. From early east-west rifting to late north-south spreading, opening of the Shikoku Basin proceeded through multiple episodes of spreading. The analysis of magnetic anomalies constrains the kinematic evolution of the basin through time and space. Two successive counter-clockwise rotations of the spreading direction are postulated, at anomaly $6(19 \mathrm{Ma})$ and at anomaly 5B (14 Ma), involving segmentation and rotation of the spreading ridge.
\end{abstract}

\section{Introduction}

The Shikoku Basin forms a broad fan-shaped marginal basin at the northeastern corner of the Philippine Sea plate. Spreading occurred behind the Izu Islands or volcanic arc of the Izu-Bonin arc-trench system, while the Kyushu-Palau Ridge was progressively isolated in a remnant position from late Oligocene to Middle Miocene [1-11]. Despite a high heat flow $[1,12-14]$ spreading is no longer active as no seismicity has been recorded in the basin [15]. To the south inter-arc spreading was initiated in a similar geodynamic setting and at about the same time in the Parece Vela back-arc basin $[2,16]$. At its northern end the Shikoku Basin underthrusts Japan toward the northwest in the $4000-4800 \mathrm{~m}$ deep Nankai Trough with a velocity ranging from $2.5 \mathrm{~cm} / \mathrm{a}$ [17] to $4 \mathrm{~cm} / \mathrm{a}$ [18] according to diverse estimations.

Results of Leg 58 of the Deep Sea Drilling Project $[9,19]$ confirmed that the acoustic basement is oceanic, as suggested by linear sequences of magnetic anomalies [3 5,8-10] and seismic refraction measurements $[20,21]$. Although it was established that oceanic accretion began sometime between late Oligocene and early Miocene and ceased approximatively $10 \mathrm{Ma}$ later, borehole data have not provided an unequivocal solution for the magnetic pattern observed in the Shikoku Basin. Furthermore, magnetic lineations are poorly identified in the axial and eastern portions of the northern basin. Successive versions of the evolution of the basin are thus speculative or at least incomplete. However, recent results of the Franco-Japanese Kaiko program [21] provide new insight into the late tectonic evolution of the Shikoku Basin. Although previous studies suggested that opening was achieved by roughly eastwest spreading, Kaiko surveys near the central Nankai Trough revealed completely different structural and magnetic trends. These include $\mathrm{N} 350^{\circ}$ trending transform faults disrupting $\mathrm{N} 130^{\circ}$, fan-shaped and even east-west magnetic anomalies. Le Pichon et al. [23] concluded there was a late phase of nearly north-south spreading in the central northern basin.

Magnetic anomaly and fracture zone patterns were thus re-examined over the whole basin in order to evaluate the extension of this unexpected north-south spreading system and its possible relationships with earlier spreading phases. The purpose of this paper is to give a coherent kinematic 
story of Shikoku Basin opening built on previous studies and these additional newly obtained results. Watts and Weissel's [4] model and Shih's [10] model are essentially correct for the western basin and southeastern basin respectively. Extending these to the northern basin, we find that multiple episodes of spreading occurred during the evolution of the basin from early east-west opening to late north-south spreading. Two major successive counter-clockwise rotations of the direction of spreading are postulated to take into account the observed structural and magnetic features. We will discuss the modalities of such drastic changes and their regional significance.

\section{Data}

Detailed topographic and geophysical investigations of the subducting oceanic crust at Nankai Trough have been achieved during the Kaiko program, including Seabeam, gravity, magnetic and single-channel seismic surveys [22-24]. Results of this cruise are of particular interest in the central area of the northern basin where, up to now, only scattered data were available and thus the geometry of spreading unknown. These data have been combined with already published magnetic [3-5, $8-10,25-27]$ and bathymetric data [8,28-32]. Watts and Weissel made available to this study seismic reflection profiles run by the research vessels "Conrad" and "Vema" of the Lamont Doherty Geological Observatory.

\section{Previous studies}

Models proposed for the evolution of the Shikoku Basin are mainly based on the identification of magnetic lineations and structural trends. Absolute dating is given either by correlations of magnetic anomalies with the geomagnetic reversal time scale or in-situ basement age determinations where available. Out of five drilling sites planned to reach basement (Sites 297 and 298 of DSDP Leg 31 , Sites 442,443 and 444 of DSDP Leg 58 - see locations of the DSDP sites in Fig. 1), calibration of magnetic anomaly age by paleontological dating of sediments immediately above oceanic crust has been successful only once in the Shikoku Basin.

During Leg 58 (1977-1978), Sites 443 and 444

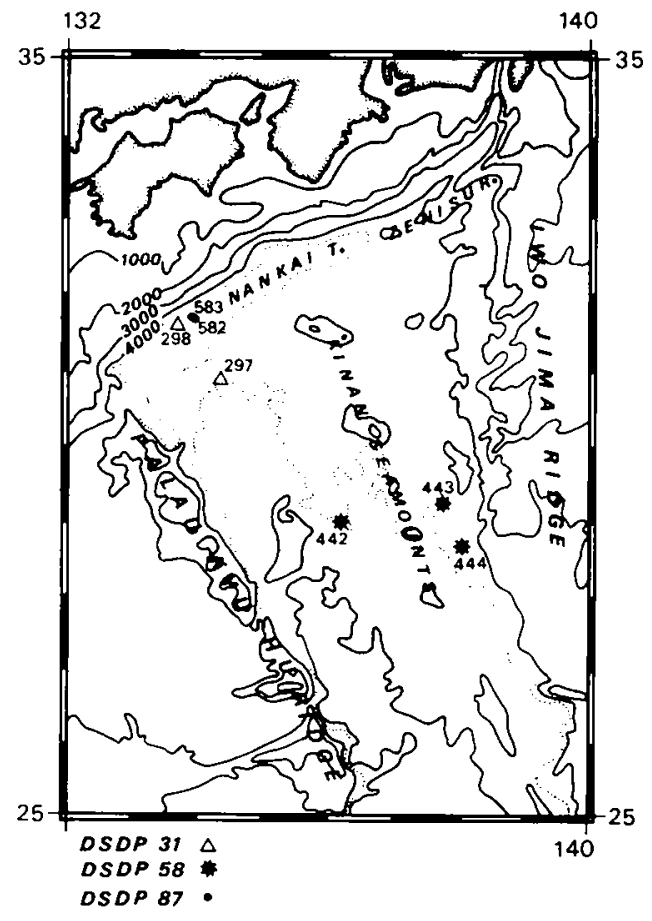

Fig. 1. Bathymetric features and locations of IPOD sites in the Shikoku Basin.

(eastern part of the basin) led to ambiguous age determinations: drilling ended in intrusive sills before basement was reached at Site 444 and sills again obscured the sediment-oceanic crust contact at Site 443. Nevertheless, a middle Miocene age was proposed for both sites, based on K-Ar age determinations [9]: 17 Ma B.P. for uppermost pillow basalt at Site 443 and 15 Ma B.P. for sill intruding sediments at Site 444. Accuracy for both ages lies within 2-3 million years.

At Site $\mathbf{4 4 2}$ only, drilling permitted sampling of the oceanic crust-oldest sediment contact and identification of magnetic anomaly 6 based on a 18-21 Ma paleontological basement age determination. Anomaly 6 recognized at this site was first proposed by Watts and Weissel [4]. Prominent peak-and-shoulder shape of western anomaly 6 is highly characteristic on magnetic profiles, at least between $27^{\circ} \mathrm{N}$ and $30^{\circ} 30^{\prime} \mathrm{N}$. South of this area, transition to the Parece Vela Basin remains unclear. It is quite advisable not to extrapolatefrom the sparse data-the Shikoku Basin magnetic lineations to these southern latitudes. In the 
same way, western anomaly 6 cannot be followed unequivocally north of $30^{\circ} 30^{\prime} \mathrm{N}$. Kobayashi and Nakada [8] assumed continuity of the lineation through a $20^{\circ}$ westward bend whereas Shih [10] inferred a left-lateral offset $70-80 \mathrm{~km}$ long. However, the proposed eastern anomaly 6 in Shih's model does not show any offset at the corresponding latitude, so that western and eastern identifications are not compatible. This reflects the great uncertainty when mapping magnetic lineations over the northeastern part of the basin.

Between latitudes $27^{\circ} \mathrm{N}$ and $30^{\circ} 30^{\prime} \mathrm{N}$, where western anomaly 6 is well defined, Watts and Weissel [4] proposed a convincing magnetic model for the western half of the basin. Well lineated magnetic anomalies, trending at a low angle to the Kyushu-Palau Ridge, abut successively the margin from older anomalies to the north to younger to the south $[4,8]$. On the basis of their correlations with the geomagnetic reversal time scale, rifting in the Shikoku Basin began about 27 Ma B.P. or 25 Ma B.P. at anomaly 7 or $6 \mathrm{C}$ (also [10]), and propagated southward until the whole basin was rifted at about 23 Ma B.P. (anomaly 6B). Roughly east-west spreading proceeded for a few million years and generated magnetic lineations 6B through 5E (19 Ma B.P.). Anomaly 5E lies in the proximity of the geometrical center of the basin.

Beyond this western well developed sequence the eastern counterpart is poorly recognizable. Attempts to interpret the whole magnetic pattern as two symmetric sequences about a single spreading axis, tentatively anomaly $5 \mathrm{E}[4]$ or $5 \mathrm{D}$ [8.9], do not satisfactorily explain the morphologic, structural and magnetic contrast between eastern and western domains. Extending $W$ atts and Weissel correlations eastwards, Shih [10] proposed a more coherent model for the southern basin. His identification of magnetic lineations is in good agreement with the various age determinations at IPOD sites. The spreading axis, namely anomaly $5 \mathrm{~B}$ (15 Ma B.P.), is not located at the geometrical center of the basin, taken half-way between the base of the Kyushu-Palau Ridge and the base of the Izu Ridge as seen from seismic reflection profiles, but is rather off-centered to the east. Similar asymmetric development is commonly observed in other back-arc basins [33]. Such a geometry implies either asymmetric spreading or later destruction of part of the oceanic crust next to the volcanic arc. as will be discussed in a later section.

Kobayashi and Nakada [8] have shown that western anomaly 6 marks the boundary between unfaulted, smooth basement to the west and highly fractured, rugged basement with relief up to $1 \mathrm{~km}$ to the east. This sharp change in basement morphology reflects a sudden decrease of the spreading rate to about half its value $[4,10]$. Shih $[10]$ further pointed out the increasing obliquity of magnetic lineations in the eastern basin, from anomaly $5 \mathrm{E}$ to $5 \mathrm{~B}$. The youngest anomalies are oriented $\mathrm{N} 140^{\circ}$ to $\mathrm{N} 130^{\circ}$, which is significantly different from the $\mathrm{N} 170^{\circ}$ trend of older anomalies. Sequences of oblique anomalies in the eastern basin do not exceed $120 \mathrm{~km}$ in length as opposed to the western basin where anomaly 6B for example is more than $600 \mathrm{~km}$ long. Finally, these short sequences of magnetic lineations are disrupted by oblique transform faults whereas prior to anomaly 6 the spreading direction was much more east-west. Shih [10] concluded that the pole of opening of the Shikoku Basin shifted at about anomaly 5E (18-19 Ma B.P.), resulting in a counter-clockwise rotation of the spreading direction. In a later section, we extend Shih's model toward the central latitudes of the basin to further explore the modalities and consequences of this major reorganization of spreading.

Although Shih's model [10] is a major step forward in understanding the evolution of the Shikoku Basin, it does not attempt to explain the Kinan Seamount Chain. This chain is a major topographic feature of the eastern and central basin, well expressed in the bathymetry as segmented en-échelon volcanic highs of various dimensions [8.34] consisting of isolated circular seamounts to more sizeable $100 \mathrm{~km}$ long portions. Note that the overall $\mathrm{N} 160^{\circ}$ trend of the chain (Fig. 1) does not reflect the northwesterly direction of individual segments. Moreover, subtle changes occur from $\mathrm{N} 125^{\circ}$ trending segments in the south to $\mathrm{N} 105^{\circ}$ when approaching Nankai Trough. Based on studies of dredged samples, the Kinan Seamount Chain is tholeiitic in type and late Middle Miocene in age (12-14 Ma B.P. [8]). After IPOD drilling, an off-ridge origin was suggested $[9,34,35]$ based on the widespread occurrence of sills at various sites. It is clear that the volcanic edifices of the Kinan Seamount Chain post-date and cut into the fossil spreading ridge 
and in that sense they represent a post-spreading and off-ridge volcanic activity, i.e. post- and offthe $15 \mathrm{Ma}$ accreting boundary. However, the geometrical organization of these volcanic features cannot be fortuitous; the Kinan Seamount Chain may well be the expression of an aborted specific stage of seafloor spreading in the Shikoku Basin, as it was first interpreted by Kobayashi and Nakada [8].

In any case, the two latest anomaly interpretations by Kobayashi and Nakada [8] and Shih [10] pointed out a much more irregular opening towards cessation of spreading, involving successive spreading events rather than a unique two-limb process at a single accreting boundary.

\section{New results}

Although previous studies recognized limited patterns of magnetic lineations in the axial northern Shikoku Basin, the quality of identification in this area is poor due to sparse data. The Kaiko program made available detailed contoured maps of geophysical data all along the Nankai Trough, including the eastern and western ends and the axial portion of the trench. Over this last region, these data were expected to locate the fossil accreting boundary of the Shikoku Basin. Seismic reflection-based maps of the oceanic crust as it enters the subduction zone led to a major discovery. Although the main magnetic sequence is oriented $\mathrm{N} 130^{\circ}$, which is similar to the direction found further south in the axial and southeastern basin, part of the anomalies are distupted by nearly north-south trending fracture zones, interpreted as transform faults related to the latest spreading system in the basin. We briefly discuss below results of the central Nankai Trough survey conducted by Le Pichon et al. [22-24].

The $\mathrm{N} 350^{\circ}$ trending fracture zones have been mapped in detail, including one between two portions of fossil ridge crest. Fig. 2 is a seismic reflection profile run along the southern boundary of the surveyed area, showing two of these major faults. Vertical offset of the oceanic basement is about $800 \mathrm{~m}$ for both fractures. The eastern one appears as an important magnetic and structural discontinuity (Fig. 3a, b), well expressed in a 50 $\mathrm{km}$ long valley. Converted depth to the basement reaches $7000 \mathrm{~m}$ half-way between the two offset portions of fossil ridge crests. The morphological expression of the valley greatly diminishes beyond both crests, as expected for the transition from the active portion of transform movement to the inactive fracture zone. These basement faults do not affect the sediment fill, mainly hemipelagites. This implies that they are contemporaneous with emplacement of the oceanic crust and generation of

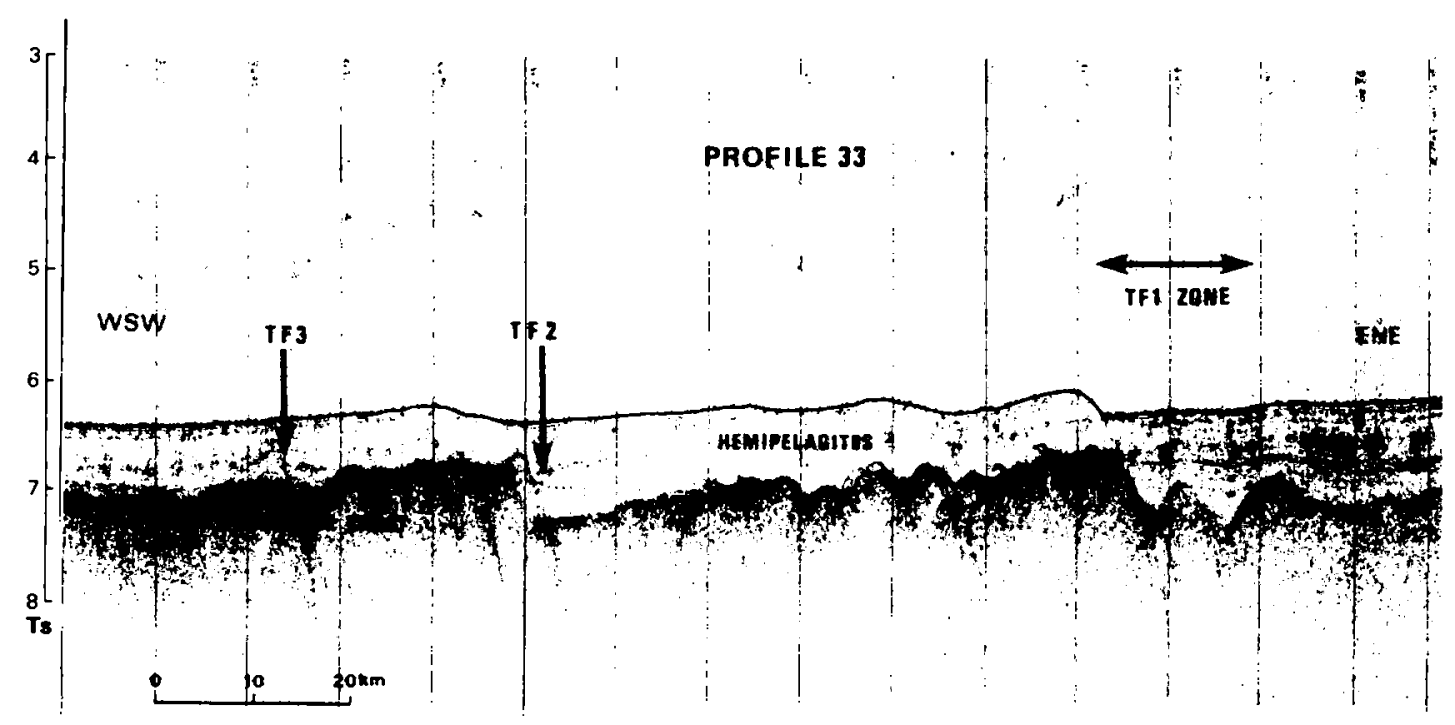

Fig. 2. Single-channel seismic profile 33 from Le Pichon et al. [23] run during Leg 1 of the Kaiko program (see location of this profile in Fig. 3b). Locations of transform faults TF1, TF2 and TF3 are also shown. 

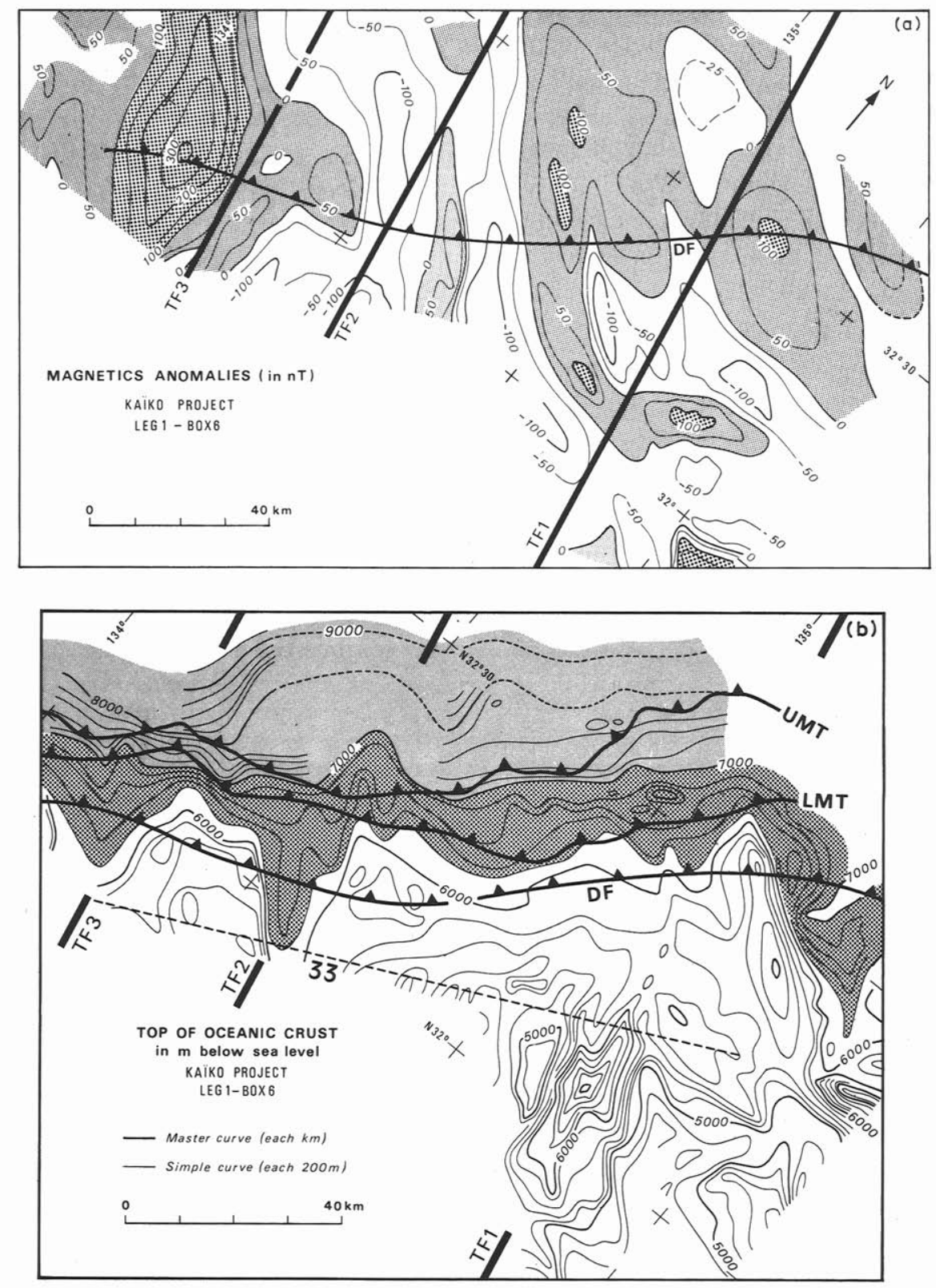

Fig. 3. (a) Map of magnetic anomalies over the central Nankai Trough from Le Pichon et al. [23]. Thick lines locate the main transform faults TF1, TF2 and TF3. Positive anomalies are grey, negative white. (b) Acoustic basement map, depth below the sea level, from Le Pichon et al. [23]. DF: deformation front; $L M T$ : lower main thrust; UMT: upper main thrust.

magnetic anomalies, and cannot be related to any type of late tectonic deformation affecting the oceanic plate at the Nankai consuming boundary.

Fig. 3a shows the magnetic pattern and the location of the inferred transform faults. Along the western boundary lies a positive magnetic anomaly of high amplitude oriented $\mathrm{N} 160^{\circ}$. This anomaly can be followed southward on previous magnetic profiles out of the surveyed area. It clearly belongs to the older set of magnetic lineations and was thus generated during the first phase of spreading. East of it, the main magnetic 


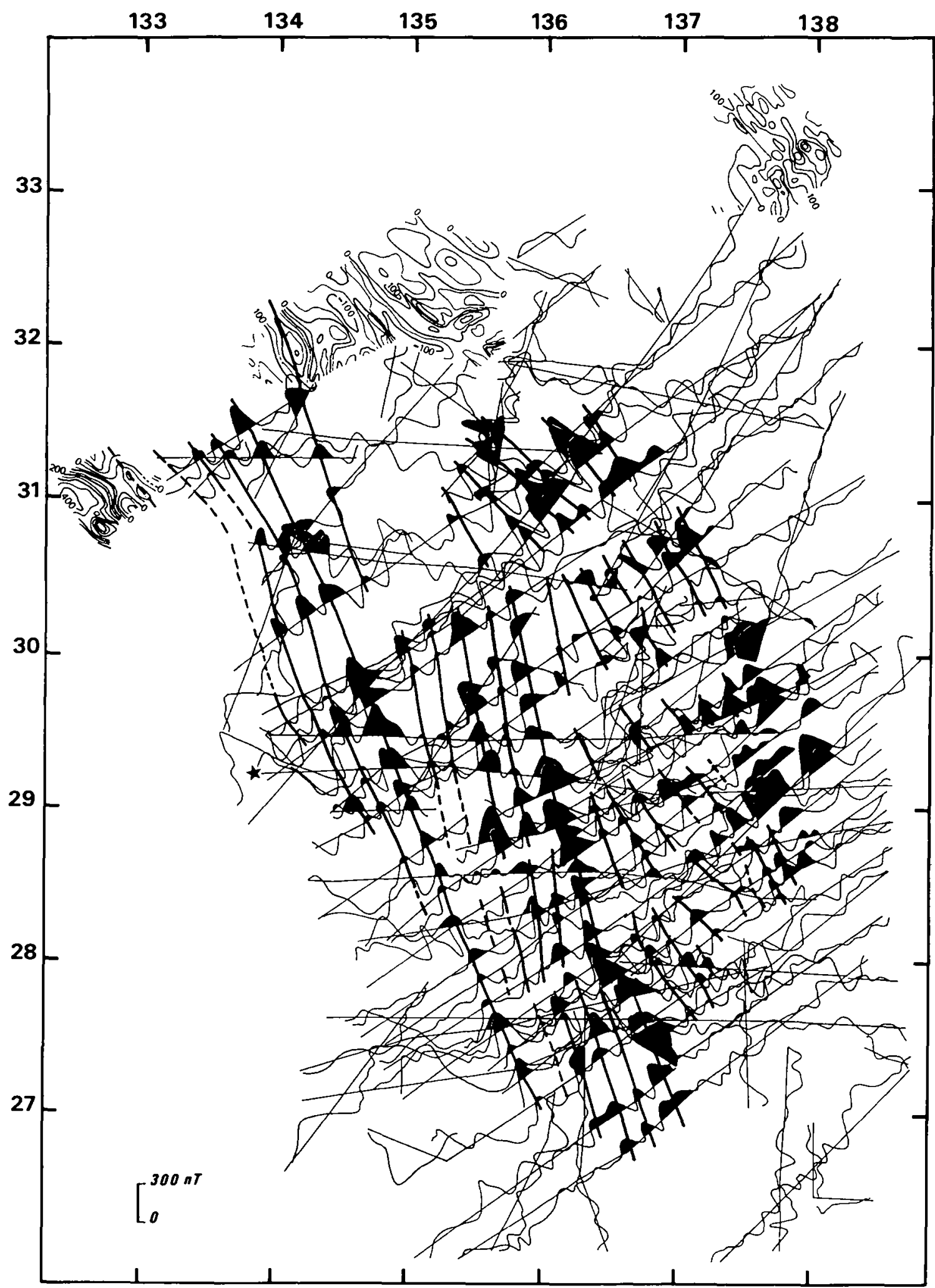

Fig. 4. Magnetic profiles from the compilation of Kobayashi and Nakada [25] and identification of magnetic lineations. The star locates profile Vema 2817. 
and structural fabric is oriented $\mathrm{N} 130^{\circ}$. This set of anomalies would correspond to very oblique spreading if we consider a $\mathrm{N} 170^{\circ}$ spreading direction. In any case, the magnetic pattern increases in complexity towards the east. Some of the lineations seem to progressively rotate from $\mathrm{N} 130^{\circ}$ to $\mathrm{N} 100^{\circ}$, so that they become more perpendicular to the north-south spreading direction as they get closer to the main transform fault TF1. Directions of the assumed fossil ridge and magnetic lineations related to it are highly speculative: west of transform fault $T F 1$, the ridge is progressively buried under the accretionary prism whereas east of it, we approach the limit of the surveyed area and no obvious correlation between magnetics and basement morphology can be made. We see two explanations for such a complex geometry:

(1) The whole magnetic pattern observed is the result of a north-south spreading system. The ridge segments first trended obliquely, and towards cessation of spreading, these segments were partly re-organized perpendicular to the spreading direction.

(2) The $\mathrm{N} 130^{\circ}$ sequence is contemporaneous to anomalies mapped further south, possibly anomaly $5 \mathrm{E}$ to $5 \mathrm{~B}$, but was then disrupted by local northsouth spreading. In the latter case, the transform faults would cut within older oceanic crust, and tectonic disturbance of the sediments in their troughs would be expected.

Examination of the Lamont seismic reflection profiles indicates no such north-south basement structure, neither south of the surveyed area nor on the western side towards the Kyushu-Palau Ridge. On the eastern side, little data is available but we believe that oceanic crust generated by north-south spreading does not extend beyond $136^{\circ} \mathrm{E}$, where the lineation trend is back to a $\mathrm{N} 160^{\circ}$ value. Le Pichon et al. [23] concluded that most of this system has now disappeared into subduction and is only preserved in the axial portion.

\section{Evolution of the Shikoku Basin}

Fig. 5 is our preferred model for the magnetic lineations of the Shikoku Basin based on the magnetic data of Fig. 4. Most of the magnetic profiles from the compilation of Kobayashi and Nakada [25] are shown together with the con- toured magnetic maps of the Kaiko surveys. Interpretation of Fig. 5 takes into account the following results:

(1) We confirm the Watts and Weissel [4] identification for the western and northwestern basin - including a more detailed analysis from anomaly 6B to anomaly 6-and Shih's [10] model for the eastern basin.

(2) We extend Shih's [10] model towards the central basin around $31^{\circ} \mathrm{N}, 136^{\circ} \mathrm{E}$. This area is highly relevant to the basin history: we demonstrate that an oblique set of magnetic anomalies $5 \mathrm{E}$ or $5 \mathrm{D}$ through $5 \mathrm{~B}$ cuts into the older sequence as a result of the first shift in the pole of opening.

(3) A hypothetical model is proposed for the northeastern basin. The two latest magnetic interpretations $[8,10]$ agree neither on the location nor on the age of the magnetic lineations in this area, where data are sparse and thus the quality of interpretation poor. Although our model also differs from previous ones, it came out as the most likely solution when attempting to kinematically reconstruct the basin evolution from seafloor spreading patterns.

(4) The Kaiko survey over the axial northern basin outlined the geometry of spreading during the late phase of opening. Magnetic lineations and basement structures are compatible with a northsouth spreading system. This reorganization is the result of a major shift of the pole of opening. Ridge segments became parallel to the Nankai Trough and spreading stopped.

\subsection{Rifting of the Shikoku Basin}

Exact timing for the beginning of rifting in the Shikoku Basin cannot be inferred from the analysis of magnetic anomalies, because the older oceanic crust has now been subducted along Nankai Trough. If we assume that rifting was initiated at similar ages for both the Shikoku and Parece Vela Basins, rifting probably began at Middle Oligocene time ( $30 \mathrm{Ma}$ B.P.) on the basis of the identification of anomaly 10 in the central region of the Parece Vela Basin and the age of cessation of volcanism on the Kyushu-Palau Ridge [16]. According to Watts and Weissel [4] the oldest anomaly in the Shikoku Basin is anomaly 7 (26 Ma B.P.) located at the western end of Nankai Trough (Figs. 4 and 5), but the northward extension and thus the origin of this positive anomaly 


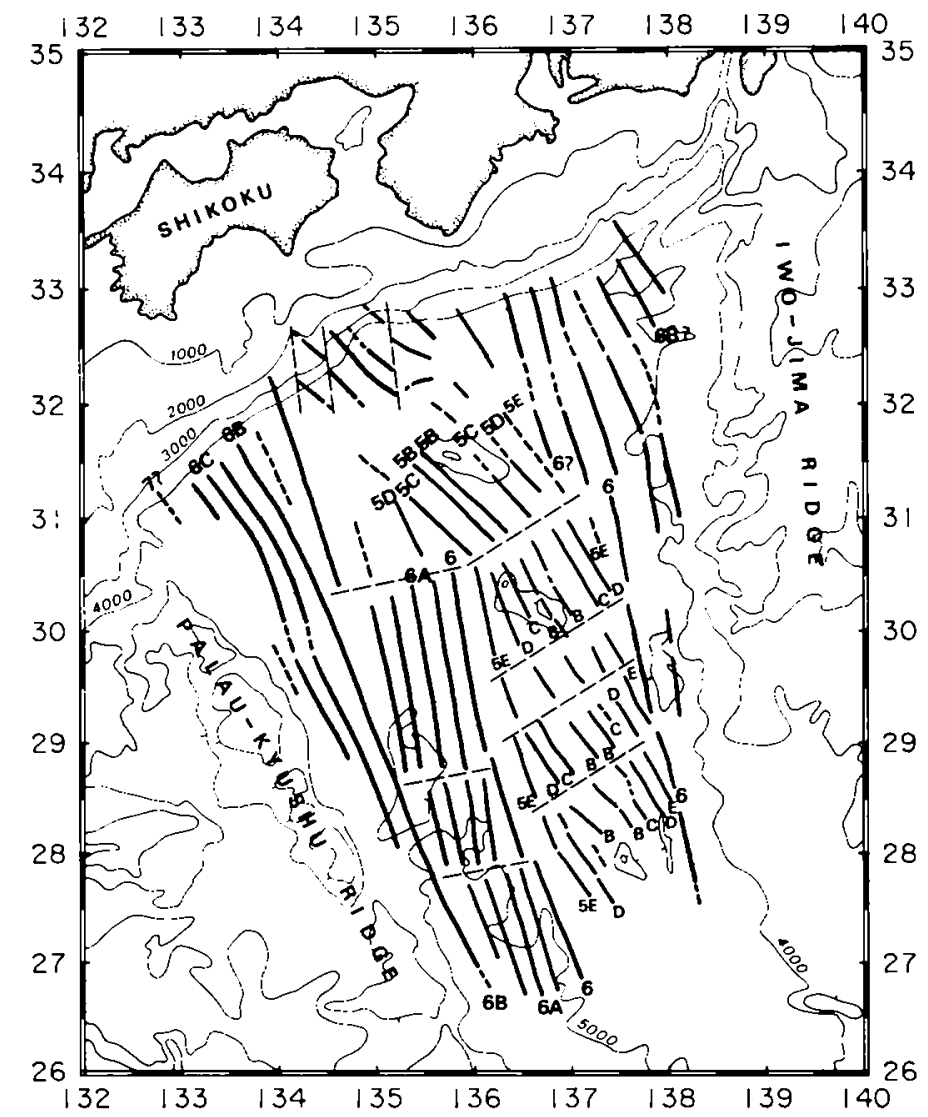

Fig. 5. Fracture zones pattern and main magnetic anomalies in the Shikoku Basin.

remains unclear (see magnetic mapping around southwest Japan [26]). If identification of anomaly 7 is correct, the Shikoku Basin was opening at a rate of about $2 \mathrm{~cm} /$ a during the very early stage of spreading. The spreading rate then increased by a factor of two and opening at a rate of $4 \mathrm{~cm} / \mathrm{a}$ proceeded until the whole basin was rifted. These rates are readily derived from Fig. 5. Our identification of magnetic lineations along the KyushuPalau Ridge is similar to those proposed by Watts and Weissel [4] and Kobayashi and Nakada [25]. In both models and in our study, anomaly $6 \mathrm{~B}$ is assumed to be continuous from the southern latitudes of the basin to the Nankai Trough. Shih inferred a left-lateral offset of about $40 \mathrm{~km}$ around $30^{\circ} \mathrm{N}$, but correlation of anomaly $6 \mathrm{~B}$ peak from profile to profile without any discontinuity is quite consistent. As discussed by Watts and Weissel [4], Site 297 in the proximity of the Nankai Trough is located right on this lineation. Although basement was not reached there, extrapolation from sedi- mentation rates gives an age of $23 \mathrm{Ma}$, in very good agreement with the age of anomaly $6 \mathrm{~B}$. Note that whether or not continuity of anomaly $6 \mathrm{~B}$ is assumed leads to very different kinematic reconstructions for the basin.

Along the Kyushu-Palau margin, southward propagation of rifting is well documented and generally interpreted as the effect of the proximity of the pole of opening to the southern end. Triplet $6 \mathrm{C}$ and possibly anomaly $6 \mathrm{~B}$ abut successively the margin $[4,8]$ so that the rate of southward propagation can be roughly estimated on a plot of the age of the oldest recognizable oceanic anomaly as a function of latitude, assuming that rifting at this scale of analysis is a continuous mechanism. The linearity of the Kyushu-Palau margin supports this idea. Such a plot has been done in Fig. 6; anomaly 7 of Watts and Weissel was not included because of the restrictions stated above concerning the identification of this anomaly. Although one cannot know exactly where isochrons inter- 


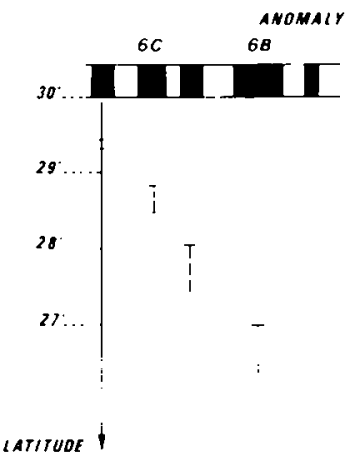

Fig. 6. Latitudes to which triplet $6 \mathrm{C}$ and anomaly $6 \mathrm{~B}$ abut the Kyushu-Palau margin. The rate of southward rifting propagation is about $30 \mathrm{~cm} / \mathrm{a}$, and seems quite constane for the total duration of the rifting event.

cept the arc crust-oceanic crust boundary, it is possible to point out the latitude to which a given anomaly is not recorded any more on magnetic profiles. This occurs where the lateral extent of the magnetic body corresponding to a positive or negative magnetic polarity event becomes too small to produce a resolvable signal.

The approximate rate of southward propagation appears to be constant at about $30 \mathrm{~cm} / \mathrm{a}$. which is an order of magnitude greater than the opening rate. This high propagation rate is consistent with the low strength of the volcanic arc. already thermally reduced before rifting.

At this rate, the junction with the Parece Vela Basin was established $22 \mathrm{Ma}$ B.P. Before that time the Shikoku Basin was not completely rifted while spreading was already active in the Parece Vela Basin. Spreading first started in the central latitudes of the Parece Vela Basin and then propagated north and south [16]. If we assume that the volcanic arc of the Izu-Bonin arc-trench system acted as a single rigid body during the opening of both marginal basins, then considerable amount of stretching should be found in the transition zone between the Shikoku and Parece Vela Basins, before both propagating tips joined together. This could best explain the diffuse magnetics of this narrow but deep zone.

\subsection{First spreading phase: from anomaly $6 B$ to} anomaly 6

From anomaly 6B to the western anomaly 6. magnetic lineations are generally interpreted as continuous and more or less parallel. However peak-to-peak correlations suggest some discontinuity zones, unless dramatic bends of the accreting ridge are assumed. In our model, the magnetic pattern for that period of time is disrupted by three transform faults (Figs. 4 and 5). Left-lateral offset averages $20 \mathrm{~km}$ for the two southernmost fractures but reaches at least $40 \mathrm{~km}$ for the northern one. The $\mathrm{N} 80^{\circ}$ spreading direction inferred from these discontinuity lines indicates a change in the mode of spreading at anomaly 6B time. Adjustment of the accreting boundary to this new direction of spreading involved segmentation of the ridge before rotation and creation of these new transform faults.

A model for such an adjustment was first described by Menard and Atwater [36], and applied to the north-eastern Pacific. Orthogonality between ridge segments and the new direction of spreading is achieved through asymmetrical spreading. Asymmetry progressively reverses in space from one end of the ridge segment to the other end. In the case of a clockwise rotation. fast-spreading northern and slow-spreading southern ends are expected for each of the segments. True relative plate motions may be inferred from the spreading rate half-way between both ends. Note that the propagating rift model $[37,38]$ does not apply here probably because there was no pre-existing transform fault to initiate such a process.

As stated above, this reorganization of the spreading system occurred slightly after anomaly 6B. At that time, spreading became efficient over the whole basin, in terms of length of ridge and rate of spreading. With the increasing length of the accreting boundary, ridge push may have become important enough to modify the force balance (i.e. the resultant of the forces applied at the plate boundaries) and thus plate motions in the area. The rate of rift propagation being an order of magnitude greater than the rate of spreading, a rapid transition from rift push to ridge push is expected, and the corresponding change in the force balance should also be rapid. A similar development for the same period of time in the Parece Vela Basin may also have contributed to such a modification. Although only a minor shift of the pole of opening is required to explain the observed magnetic pattern, new conditions prevailed in the Shikoku Basin at the end of this first 


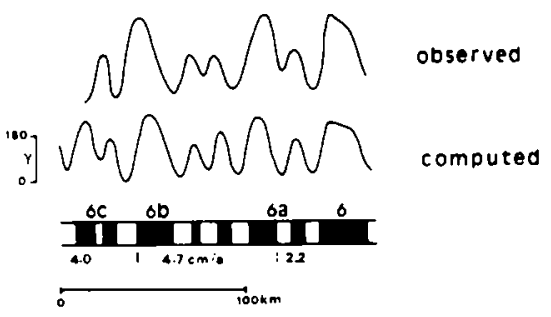

Fig. 7. Profile Vema 2817 of Watts et al. [7] representative of the western basin (see location in Fig. 4). Computed model is based on the geomagnetic time scale of Lowrie and Alvarez [39]. A Gaussian distribution function with $\sigma=3 \mathrm{~km}$ was used between two blocks of opposite magnetization, as proposed by Watts et al. [7] for the Shikoku Basin. The spreading direction trends $\mathrm{N} 65^{\circ}$ before $6 \mathrm{~B}$ and $\mathrm{N} 80^{\circ}$ from $6 \mathrm{~B}$ to 6 .

spreading phase, including ridge segmentation and transform fault development.

Fig. 7 is the magnetic model proposed by Watts and Weissel [4] for that period of time, slightly modified to take into account our preferred spreading rates and spreading directions. Geometric adjustment of the ridge following this change in spreading direction was achieved within a relatively short time span, less than 1 million years. The corresponding rate during that time was about $4.7 \mathrm{~cm} / \mathrm{a}$ to the north and $4.1 \mathrm{~cm} / \mathrm{a}$ to the south. High spreading rates between 4 and $5 \mathrm{~cm} / \mathrm{a}$ prevailed until anomaly $6 \mathrm{~A}$ time. Spreading rates then rapidly decreased to a value of about $2 \mathrm{~cm} / \mathrm{a}$ at anomaly 6 (20 Ma B.P.). As mentioned previously, the western anomaly 6 is a marked boundary in magnetics and bathymetry. West of it, oceanic crust was generated at high to moderate spreading rates; basement topography is quite smooth with low ridge-and-trough relief. On the other hand, the rate of spreading was about $2 \mathrm{~cm} / \mathrm{a}$ in the eastern basin, and the associated basement topography is very rugged.

\subsection{Second spreading phase: from anomaly 6 to} anomaly $5 B$

Magnetic lineations 5E to 5B mapped by Shih $[10]$ in the east-central and southeastern sectors of the Shikoku Basin nicely demonstrate a major shift in the pole of opening, occurring after anomaly 6 time. Based on the examination of seismic reflection profiles and disruption of magnetic lineations, the shift was probably more important than proposed by Shih [10]. The new direction of spreading is $\mathrm{N} 55^{\circ}$ rather than the
N70 direction in Shih's model, as can be seen in Fig. 5. The amount of counter-clockwise rotation thus reaches $25^{\circ}$ if we consider $\mathrm{N} 80^{\circ}$ as the previous spreading direction. Note that anomaly 6 is already rotated in a counter-clockwise fashion so that small $\mathrm{N}^{\circ} 0^{\circ}$ trending offsets do not exist any more for this anomaly: the two southernmost $\mathrm{N} 80^{\circ}$ transform faults are "deactivated" as a consequence of rotation of anomaly 6 . We conclude that conditions for a counter-clockwise rotation of the ridge were already set by that time, in agreement with the sudden decrease of the spreading rate. However, the $\mathrm{N} 55^{\circ}$ orientation became established at anomaly $5 \mathrm{E}$ and the ridge was broken into several segments, at least five, each about $100 \mathrm{~km}$ long.

Up to now, no model has been proposed for the northern segment, in the central latitudes of the basin. Fig. 8 shows magnetic profiles in this area, selected from the Kobayashi and Nakada [25] magnetic compilation. Two-peak anomaly 6A and western anomaly 6 , are located at the lower left corner. They do not extend north of $30^{\circ} 30^{\prime} \mathrm{N}$ where a set of oblique lineations is found. Correlation of these profiles with the geomagnetic reversal time scale of Lowrie and Alvarez [39] is shown in Fig. 9, assuming that this oblique sequence corresponds to anomalies $5 \mathrm{E}$ through $5 \mathrm{~B}$. A reasonably good fit has been obtained using a 1.8 $\mathrm{cm} /$ a spreading rate, which should be compared to the $1.7-1.5 \mathrm{~cm} / \mathrm{a}$ spreading rates proposed by Shih further south [10].

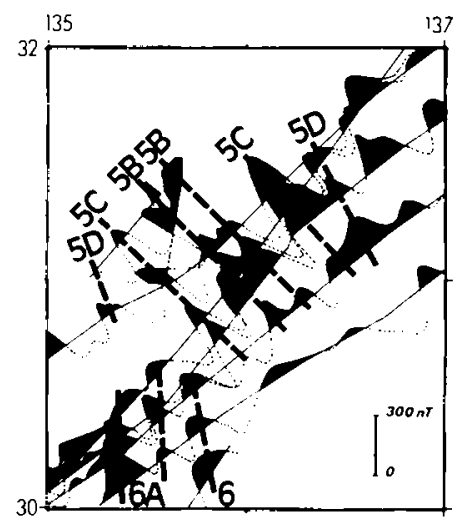

Fig. 8. Magnetic profiles in the central Shikoku Basin, selected from Kobayashi and Nakada [25]. The oblique set of magnetic anomalies cuts into the older sequence, including western anomaly 6. 


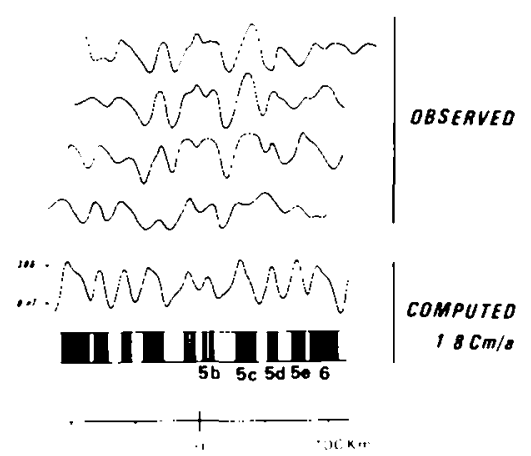

Fig. 9. Some of the magnetic profiles of Fig. 8. projected at azimuth $\mathrm{N} 55^{\circ}$, and computed model for a $1.8 \mathrm{~cm} / \mathrm{a}$ halfspreading rate.

We see two solutions that could match the observed geometry: (1) anomalies $5 \mathrm{E}$ to $5 \mathrm{~B}$ cut into the older oceanic crust, as a consequence of the shift of the pole of rotation; the older spreading ridge would have been abandoned north of $30^{\circ} 30^{\prime} \mathrm{N}$, but only rotated in the southeastern basin; (2) the same ridge generated older and younger anomalies north of $30^{\circ} 30^{\prime} \mathrm{N}$, assuming rotation of the ridge for the northern basin similar to the southeastern basin. The assumed mechanism would be a propagating or jumping ridge process in the first case, and a simple ridge rotation in the second case. In that latter case, the pre-existing offset of the ridge at anomaly 6 at the critical latitude would have to be at least $80 \mathrm{~km}$ long. We have shown that at anomaly $6 \mathrm{~B}$ time a set of ${\mathrm{N} 80^{\circ}}^{\circ}$ transform faults had been activated, including one at this latitude, but that the amount of offset did not probably reach the required 80 $\mathrm{km}$. Such a large offset would imply an average spreading rate of $2 \mathrm{~cm} /$ a between anomaly $6 \mathrm{~B}$ and anomaly 6 just north of the transform fault. Although we do expect a lower spreading rate at this location as a result of asymmetric spreading described in the former section, the rate of spreading should rapidly come back to a normal value. On the other hand, even a small offset may have initiated a propagating ridge process. We thus suggest that in the central latitudes of the basin the ridge broke through and rapidly propagated into older oceanic crust, in response to the $25^{\circ}$ counter-clockwise rotation of the direction of spreading. Clearly more data is needed to understand in detail the geometry of spreading through space and time over this critical area.

\subsection{Eastern limb}

According to our model, the western Shikoku Basin represents the western limb of the first spreading phase whereas both eastern and western limbs of the second spreading phase are totally identified, symmetrically about anomaly 5B. A question arises immediately: where is the eastern limb generated during the first spreading phase, symmetric to the well lineated magnetic pattern of the western limb?

Along the western flank of the Izu Ridge, the westernmost ridge of the volcanic arc, small amplitude magnetic anomalies and thick sediment cover make it impossible to delineate the oceanic crust-arc crust boundary in magnetics or bathymetry $[32,40,41]$. However, asymmetry between western and eastern limbs is readily observable on seismic reflection profiles. North of $28^{\circ} \mathrm{N}$, oceanic crust does not extend beyond $138^{\circ} 30^{\prime} \mathrm{E}$. Between $28^{\circ} \mathrm{N}$ and $30^{\circ} \mathrm{N}$ anomaly $5 \mathrm{~B}$ is thus only $100 \mathrm{~km}$ away from the Izu Ridge margin whereas the distance to the Kyushu-Palau Ridge margin reaches $250 \mathrm{~km}$. If we consider Shih's [10] model, the asymmetry does not exceed $10 \%$ from anomaly 6 to anomaly 5B, corresponding to a $1.7 \mathrm{~cm} / \mathrm{a}$ western spreading rate and a $1.5 \mathrm{~cm} / \mathrm{a}$ eastern spreading rate. Thus, before anomaly 6 time, a high degree of asymmetry is required. The possibility of a totally asymmetric opening with no spreading on the volcanic arc side has been investigated by Watts and Weissel [4] and discussed by Klein and Kobayashi [9]. Such a strong asymmetry is in disagreement with the observed wavelengths of magnetic anomalies which are not significantly different at the base of both western and eastern margins.

It is most likely that the active volcanic line of the Izu-Bonin Arc extended towards the basin and built over its eastern limb. This would best explain the diffuse boundary in bathymetry and magnetics between arc crust and oceanic crust on the volcanic side, as well as the anomalous basement depth of the eastern margin pointed out by Kobayashi [34]: basement is there $500 \mathrm{~m}$ shallower than that of the western margin. Further, the $30^{\circ}$ angle between the north-south trending margin and the $\mathrm{N} 150^{\circ}$ trend of the oldest magnetic lineations is incompatible with a simple rift propagation mechanism. Such an effect would not exceed a few degrees as seen for the western margin, and in any case 
angles should be equal on both sides. We conclude that the present eastern margin of the Shikoku Basin is not the original rifted margin but rather the limit of extension of the volcanic arc onto Shikoku Basin oceanic crust. This is readily apparent in the southern latitudes where off-centering of the spreading axis is maximum but also exists in the northern latitudes where the margin-magnetic anomalies angle is maximum.

Note that both asymmetric spreading and later destruction of the arc-sided limb would be expected in the case of a trenchward component of the motion of the back-arc region in an absolute frame fixed with respect to the mantle: (1) the accreting boundary trailing side-i.e. western side - may spread faster as predicted by fluid mechanical models [42];. (2) apparent migration of the volcanic arc onto the back-arc area is also expected. In this simple view we assume that the source of magma in the subducting slab remains fixed with respect to the mantle, which may obviously not be the case. However, the scheme is still valid if the trench retreats faster than the location of magma generation does.

In the southern latitudes, the oldest anomalies recognized at the base of lzu Ridge are anomalies 6A and 6. Our identification for these anomalies agrees with Shih's [10]. Further north, most of the eastern limb has been preserved. However magnetic lineations and basement structures are poorly identified over the northeastern part of the Shikoku Basin. Peak-to-peak correlations for magnetic lineations are not straightforward mainly because density of coverage is low. The disruption of the magnetic pattern may well be the consequence of the structuralization of the Bonin Arc [43]: oceanic crust in that portion of the Shikoku Basin must have recorded the colliding tectonics of the arc, Zenisu Ridge being the most spectacular evidence. Although the exact location of magnetic anomalies is uncertain, eastern anomalies $6 \mathrm{~B}$ to 6 are likely to be found in this area. We propose a left-lateral offset of anomaly 6 just north of $31^{\circ} \mathrm{N}$, in agreement with our model for western anomalies.

\section{Discussion and conclusions}

To test our hypothesis concerning the age of the different spreading phases in the Shikoku
Basin, we compiled 83 available heat flow measurements carried out at various locations in the basin. These include the detailed analysis of heat flow in the Nankai Trough area of Yamano et al. [14] for the northern basin and isolated measurements for the southern half $[12,13,44]$. The results of this compilation are listed in Table 1. The central trench refers to the area where north-south transform faults and east-west magnetic anomalies were found. The central basin is that part of the basin younger than anomaly 6 . Where possible, "A" environment measurements were sorted out as it is now well known that only these are reliable for age of oceanic crust purposes.

In Table 2, only the " $A$ " environment measurements were used. The standard deviation thus reduces to about half its value in the central basin and central trench areas. Although data display considerable scatter, "A" measurements show that the central basin and the central trench areas have high heat flow, around $105-125 \mathrm{~mW} / \mathrm{m}^{2}(2.5-3.0$ HFU). An age window of 12-14 Ma was tentatively assigned to the central trench area, where the highest heat flow values are found. The central basin corresponds to the second spreading phase, between anomaly 6 and anomaly 5B, i.e. 19 to 14 $\mathrm{Ma}$. The eastern trench and western trench regions were considered as the best representative areas for the 25 to 19 Ma period, including rifting and the first spreading phase.

Heat flow values versus age are plotted in Fig. 10 and compared to the standard heat flow law of

\section{TABLE 1}

Heat flow in the Shikoku Basin (all measurements)

\begin{tabular}{lcll}
\hline & $\begin{array}{l}\text { Number } \\
\text { of mea- } \\
\text { surements }\end{array}$ & $\begin{array}{l}\text { Heat flow } \\
\text { value } \\
\left(\mathrm{mW} / \mathrm{m}^{2}\right)\end{array}$ & $\begin{array}{l}\text { Standard } \\
\mathrm{dev} . \\
\left(\mathrm{mW} / \mathrm{m}^{2}\right)\end{array}$ \\
\hline $\begin{array}{l}\text { Western Trench } \\
\text { turbidites environment }\end{array}$ & 11 & 73 & 20 \\
$\quad \begin{array}{l}\text { whole area } \\
\text { Central Trench }\end{array}$ & 20 & 63 & 19 \\
$\quad$ "A"environment & 6 & 123 & 25 \\
$\quad$ whole area & 20 & 98 & 46 \\
Eastern trench & 7 & 78 & 23 \\
Western basin & 9 & 53 & 31 \\
Central basin & & & \\
$\quad$ "A" environment & 8 & 106 & 18 \\
$\quad$ whole area & 19 & 76 & 43 \\
Eastern basin & 8 & 54 & 22 \\
\hline
\end{tabular}


TABLE 2

Heat flow in the Shikoku Basin ("A" environment measurements)

\begin{tabular}{|c|c|c|c|c|c|}
\hline Age window & Best representative area & $\begin{array}{l}\text { Number of } \\
\text { measurements }\end{array}$ & $\begin{array}{l}\text { Observed } \\
\text { heat flow } \\
\left(\mathrm{mW} / \mathrm{m}^{2}\right)\end{array}$ & $\begin{array}{l}\text { Theoretical } \\
\text { heat flow } \\
\left(\mathrm{mW} / \mathrm{m}^{2}\right)\end{array}$ & $\begin{array}{l}\text { Deviation from } \\
\text { standard law }\end{array}$ \\
\hline $12 \cdots 14 \mathrm{Ma}$ & Central trench " $A$ " environment & 6 & 123 & 131 & $-6 \%$ \\
\hline $14-19 \mathrm{Ma}$ & Central basin " $A$ " environment & 8 & 106 & 116 & $-9 q$ \\
\hline $19-25 \mathrm{Ma}$ & $\begin{array}{l}\text { Fastern trench and western trench } \\
\text { turbidites environments }\end{array}$ & 18 & 75 & 101 & $-25 \%$ \\
\hline
\end{tabular}

Parsons and Sclater [45]. When only "A" measurements are considered, the mean values are closer to the standard law, but still lower than the theoretical value. Note that the measured values systematically underestimate the actual heat flux coming out the oceanic crust, because most of the "disturbing" effects tend to lower the surface heat flow: heating of the sediments or hydrothermal circulation within the crust. Although the mean heat flow value over the central trench area is greater than the mean value over the central basin $\left(15 \mathrm{~mW} / \mathrm{m}^{2}\right.$ in Table 2$)$ the difference may not be significant. Heat flow is expected to be higher within the trench, where convection may be sealed off. This problem is discussed in detail in Yamano et al. [14]. Their conclusion, after modelling the different thermal possibilities, is that the plate subducting at the central Nankai Trough has to be hot.

We propose that the latest north-south spreading system is responsible for the high heat flow over the central trench. This phase could be either contemporaneous with the second spreading phase recognized further south-i.e. between 19 and 15
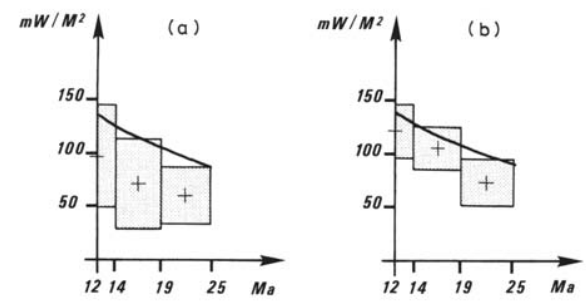

Fig. 10. Compilation of heat flow measurements plotted as a function of age. Data are combined in three age groups, corresponding to the three spreading phases. (a) includes all measurements whereas in (b) only " $A$ " measurements were plotted. The thick curve is the standard heat flow versus age relationship $473 t^{-1 / 2} \mathrm{~mW} / \mathrm{m}^{2}\left(11.3 t^{-1 / 2} \mathrm{HFU}\right.$ [45]). See text and Tables 1 and 2 for explanations.
Ma-or younger, and unless we assume that spreading stopped for a while in the Shikoku Basin, a reasonable age would lie between 15 and $12 \mathrm{Ma}$. If we assume a 19 to $15 \mathrm{Ma}$ age, then a triple junction should be found between both areas.

In any case north-south spreading aborted as it had already aborted to the south and resulted in the edification of the Kinan Seamount Chain. From rifting of the Shikoku Basin to dying of the ridge, geometry of spreading has several times been re-adjusted in order to satisfy new plate stress configurations. For the Philippine Sea plate, modifications of the boundary conditions along the subduction zones probably induced these new configurations. In particular, subduction of the accreting ridge of the Shikoku Basin, subduction of the buoyant Kyushu-Palau Ridge and Bonin Arc and opening of the Japan Sea modified the force balance along Nankai Trough through time. The accreting ridge evolved through segmentation and rotation, with a tendency to converge towards a geometry consisting of small accreting segments parallel to the trench, so that spreading stopped.

\section{Acknowledgements}

This paper is within the framework of the French-Japanese Kaiko project. Support of CNRS, IFREMER and MRE is acknowledged. The first author thanks A. Watts, J. Weissel and their colleagues for a two months' stay in Lamont Doherty Geological Observatory during which additional magnetic and seismic reflection data were obtained. We thank S. Uyeda, T. Shih and T. Hilde for helpful reviews.

\section{References}

1 D.E. Karig, Origin and development of marginal basins in the western Pacific, J. Geophys. Res. 76, 2542-2561, 1971. 
2 D.E. Karig, Basin genesis in the Philippine sea, Init. Rep. Deep Sea Drill. Proj. 31, 857-879, 1975.

3 Y. Tomoda, K. Kobayashi, J. Segawa, M. Nomura, K. Kimura and T. Saki. Linear magnetic anomalies in the Shikoku Basin, northwestern Philippine sea, J. Geomagn. Geoelectr. 27, 47-56, 1975

4 A.B. Watts and J.K. Weissel, Tectonic history of the Shikoku marginal basin, Earth Planet. Sci. Lett. 25, 239-250, 1975.

$5 \mathrm{~K}$. Kobayashi and N. Isezaki, Magnetic anomalies in the Sea of Japan and the Shikoku Basin: possible tectonic implications, in: The Geophysics of the Pacific Ocean and Its Margin, Am. Geophys. Union, Geophys. Monogr. 19. 235-251, 1976.

6 T.W.C. Hilde, S. Uyeda and L. Kroenke, Evolution of the western Pacific and its margin, Tectonophysics 38, 145-165, 1977.

7 A.B. Watts, J.K. Weissel and R.L. Larson, Sea-floor spreading in marginal basins of the western Pacific, Tectonophysics 37, 167-181, 1977.

8 K. Kobayashi and M. Nakada, Magnetic anomalies and tectonic evolution of the Shikoku inter-are basin, J. Phys. Earth 26 (Suppl.), 391-402, 1978.

9 G. deV. Klein and K. Kobayashi, Geological summary of the North Philippine Sea based on Deep Sea Drilling Project Leg 58 results, Init. Rep. Deep Sea Drill. Proj. 58, $951-961,1980$.

10 T.C. Shih, Magnetic lineations in the Shikoku Basin, Init. Rep. Deep Sea Drill. Proj. 58, 783-788, 1980.

11 T. Seno and S. Maruyama, Paleogeographic reconstruction and origin of the Philippine sea. Tectonophysics 102, 53-84, 1984.

12 T. Watanabe, M.G. Langseth and R.N. Anderson, Heat flow in back-arc basins of the western Pacific, in: Island Arcs Deep-Sea Trenches and Back-Arc Basins, Am. Geophys. Union, Maurice Ewings Ser. 1, 137-161, 1977

13 R.N. Anderson, 1980 update of heat flow in the East and Southeast Asian Seas, in: The Tectonic and Geologic Evolution of Southeast Asian Seas and Islands, D.E. Hayes, ed., Am. Geophys. Union. Geophys. Monogr. 23, 319-326. 1980.

14 M. Yamano, S. Honda and S. Uyeda, Nankai Trough: a hot trench?, Mar. Geophys. Res. 6, 187-203, 1984.

15 M. Katsumata and L.R. Sykes, Seismicity and tectonics of the western Pacific: Izu-Mariana-Caroline and RyukuTaiwan regions, J. Geophys. Res. 74, 5923-5948, 1969.

16 C.L. Mrozowski and D.E. Hayes, The evolution of the Parece Vela basin, eastern Philippine Sea, Earth Planet. Sci. Lett. 46, 49-67, 1979.

17 T. Seno, The instantaneous rotation vector of the Philippine Sea plate relative to the Eurasian plate, Tectonophysics 42, 209-226, 1977

18 B. Ranken, R.K. Cardwell and D.E. Karig, Kinematics of the Philippine Sea plate, Tectonics 3, 555-575, 1984.

19 H.J.B. Dick, N.G. Marsh and T.D. Bullen, Deep Sea Drilling Project Leg 58: abyssal basalts from the Shikoku Basin, their petrology and major element geochemistry, Init. Rep. Deep Sea Drill. Proj. 58, 843-872, 1980.

20 S. Murauchi, N. Den, S. Asano, H. Hotta, T. Yoshii, T. Asaruma, K. Hagiwara, K. Ichikawa. R. Sato, W.J. Ludwig, J.I. Ewing, N.T. Edgar and R.E. Houtz, Crustal structure of the Philippine Sea, J. Geophys. Res. 73, 3143-3171, 1968.
21 T. Yoshii, W.J. Ludwig, N. Den, S. Murauchi, M. Ewing, H. Hotta, P. Buhl, T. Asanuma and N. Sakajiri. Structure of Southwest Japan margin off Shikoku, J. Geophys. Res. 78, 2517-2525, 1973.

22 X. Le Pichon, K. Kobayashi, J.P. Cadet, T. liyama, K. Nakamura, G. Pautot, V. Renard and the Kaiko Scientific Crew, Project Kaiko-Introduction, Earth Planet. Sci. Lett. $83,183-185,1987$ (this issue).

$23 \mathrm{X}$. Le Pichon, T. Iiyama, H. Chamley, J. Charvet, M. Faure, H. Fujimoto, T. Furuta, Y. Ida, H. Kagami, S. Lallemant, J. Leggett, A. Murata, H. Okada, C. Rangin, V. Renard, A. Taira and K. Tokuyama, Nankai Trough and the fossil Shikoku Ridge: results of Box 6 Kaiko survey, Earth Planet. Sci. Lett. 83, 186-198, 1987 (this issue).

$24 \mathrm{X}$. Le Pichon, T. Iiyama, H. Chamley, J. Charvet, M. Faure, H. Fujimoto, T. Furuta, Y. Ida, H. Kagami, S. Lallemant, J. Leggett, A. Murata, H. Okada, C. Rangin. V. Renard, A. Taira and K. Tokuyama, The eastern and western ends of Nankai Trough: results of Box 5 and Box 7 Kaiko survey, Earth Planet. Sci. Lett. 83, 199-213, 1987 (this issue).

25 K. Kobayashi and M. Nakada, Local magnetic anomaly profile, Shikoku Basin, northwest Pacific Ocean, Contrib. Geodyn. Proj. Jpn. 77-2, 1977.

26 S. Oshima. T. Tozaki and K. Onodera, Geomagnetic anomalies at sea around southwest Japan, Rep. Hydrograph. Res. 15. March 1980.

27 S. Oshima, T. Tozaki, K. Onodera, T. Kaneko and Y. Ueda, Geomagnetic anomalies at sea around central part of Honshyu Japan, Rep. Hydrograph, Res. 16, March 1981.

28 K. Kobayashi, Underway geophysical data, Deep Sea Drilling Project Leg 58, from Yokohama, Japan, to Naha. Okinawa, in the North Philippine Sea, Init. Rep. Deep Sea Drill. Proj. 58, 843-872. 1980.

29 General Bathymetry Chart of the Oceans (GEBCO), 1979.

30 Hydrographic Department, Bathymetric chart, Central Nippon, 1982.

31 Hydrographic Department. Bathymetric chart, Southwest Nippon. 1983.

32 E. Honza and K. Tamaki, Bonin arc, in: The Ocean Basins and Margins, Vol. 7, 1983.

33 B. Taylor and G.D. Karner, On the evolution of marginal basins, Rev. Geophys. Space Phys. 21 (8), 1727-1741, 1983.

$34 \mathrm{~K}$. Kobayashi, Subsidence of the Shikoku back-arc basin. Tectonophysics 102, 105-117, 1984.

$35 \mathrm{G}$. deV: Klein, K. Kobayashi et al., Off-ridge volcanism and sea-floor spreading in the Shikoku Basin, Nature 273, 746-748, 1978.

$36 \mathrm{H} . \mathrm{W}$. Menard and T. Atwater, Changes in direction of sea-floor spreading, Nature 219, 463-467, 1968.

37 J. Shih and P. Molnar. Analysis and implications of the sequence of ridge jumps that eliminated the Surveyor Transform fault, J. Geophys. Res. 80, 4815-4822, 1975.

38 R.N. Hey, A new class of "pseudofaults" and their bearing on plate tectonics: a propagating rift model, Earth Planet. Sci. Lett. 37, 321-325, 1977.

$39 \mathrm{~W}$. Lowrie and W. Alvarez, One hundred million years of geomagnetic polarity history, Geology 9, 392-397, 1981.

40 D.F. Karig and G.F. Moore, Tectonic complexities in the Bonin arc system, Tectonophysics 27, 97-118, 1975.

41 T. Miyazaki, F. Murakami. K. Nishimura and T. Ishihara, 
Geomagnetic survey, in: Geological Investigation of the Ogazawara (Bonin) and Northern Mariana Arcs, Cruise Report 14, 79-82, 1981.

42 S. Stein, H.J. Melosh and J.B. Minster, Ridge migration and asymmetric sea-floor spreading, Earth Planet. Sci. Lett. 36, 51-62, 1977.

43 W.L. Bandy and T.W.C. Hilde, Structural features of the Bonin arc: implications for its tectonic history, Tectonophysics 99, 331-353, 1983.
44 J.G. Sclater, D. Karig, L.A. Lawver and K. Louden, Heat flow, depth, and crustal thickness of the marginal basins of the South Philippine Sea, J. Geophys. Res. 81, 309-318. 1976.

45 B. Parsons and J.G. Sclater, An analysis of the variation of ocean floor bathymetry and heat flow with age, J. Geophys. Res. 82, 803-827, 1977. 